\title{
A importância da cultura no ensino de Ciências
}

\section{La importancia de la cultura en la enseñanza de las ciencias \\ The importance of culture in science teaching}

\author{
Flávia Almeida Silva ${ }^{1}$ \\ Sérgio Choiti Yamazaki ${ }^{2}$
}

\begin{abstract}
Resumo
Este trabalho se propõe a refletir sobre a necessidade de ensinar Ciências sob uma perspectiva cultural, para que se forme em alunos a chamada cultura científica. Para tal, pretende-se identificar na epistemologia de Bachelard e Paulo Freire a importância da cultura como elemento intrínseco no estudo das Ciências, em sua própria construção e no ato de ensinar. Foi possível concluir que Bachelard e Freire, apesar de se situarem em campos distintos, apresentam similaridades quanto a necessária relevância da cultura que permeia o indivíduo e suas concepções dentro das Ciências, como a necessidade do rompimento entre o senso comum e o conhecimento científico, mostrando que o elemento cultural é fator decisivo no processo de construção do saber do indivíduo. Com base nos autores, conclui-se também que os fatores criticidade e conscientização do sujeito tornam positivo o ensino de Ciências, contrariando o viés tecnicista do ensino tradicional. No entanto, ao se adotar essa perspectiva de ensinar em prol do estabelecimento de uma cultura científica, é notório que limitações surgirão no decorrer do caminhar docente, visto que o ensino se encontra inserido em uma tradição conteudista e formulista. Porém, as vantagens dessa "nova" forma de conceber o ensino de Ciências, podem contribuir com a melhoria a longo prazo da própria sociedade.
\end{abstract}

Palavras-Chave: cultura, epistemologia bachelardiana, Freire.

\section{Resumen}

Este trabajo se propone reflexionar sobre la necesidad de enseñar Ciencias desde una perspectiva cultural, para que se forme en alumnos la llamada cultura científica. Para ello, se pretende identificar en la epistemología de Bachelard y Paulo Freire la importancia de la cultura como elemento intrínseco en el estudio de las Ciencias, en su propia construcción y en el acto de enseñar. Es posible concluir que Bachelard y Freire, a pesar de situarse en campos distintos, presentan semejanzas como la necesaria relevancia de la cultura que permea al individuo y sus concepciones dentro de las Ciencias, como la necesidad del rompimiento entre el sentido común y el conocimiento científico, que el elemento cultural es factor decisivo en el proceso de construcción del saber del individuo. Con base en los autores, se concluye también que los factores criticidad y concientización del sujeto hacen positivo la enseñanza de Ciencias, contrariando el sesgo tecnicista de la enseñanza tradicional. Sin embargo, al adoptar esta perspectiva de enseñar en pro del establecimiento de una cultura científica, es notorio que las limitaciones surgirán en el transcurso del caminar docente, ya que la enseñanza se encuentra inserta en una tradición conteudista y formulista. Sin embargo, las ventajas de esta "nueva" forma de concebir la enseñanza de las ciencias, indican contribuir a una mejora a largo plazo de la propia sociedad.

Palabras claves: la cultura, la epistemología bachelardiana, Freire.

\footnotetext{
${ }^{1}$ Mestranda no Programa de Pós-Graduação em Educação Científica e Matemática; Bolsista PIBAP/UEMS; Licenciada em Física; Universidade Estadual de Mato Grosso do Sul; Dourados, Mato Grosso do Sul, Brasil; amdflavia@ hotmail.com.

${ }^{2}$ Doutor em Educação Científica e Tecnológica; Programa de Pós-Graduação em Educação Científica e Matemática; Universidade Estadual de Mato Grosso do Sul; Dourados, Mato Grosso do Sul, Brasil; sergioyamazaki@gmail.com.
} 


\begin{abstract}
This work aims to reflect on the need to teach science from a cultural perspective, so that the so-called scientific culture is formed in students. For this, it is intended to identify in the epistemology of Bachelard and Paulo Freire the importance of culture as an intrinsic element in the study of Sciences, in its own construction and in the act of teaching. It was possible to conclude that Bachelard and Freire, although located in different fields, present similarities as to the necessary relevance of the culture that permeates the individual and their conceptions within the Sciences, such as the need to break between common sense and scientific knowledge, showing that the cultural element is a decisive factor in the process of constructing the knowledge of the individual. Based on the authors, it is also concluded that the criticality and awareness of the subject make positive the teaching of science, contrary to the technicist bias of traditional teaching. However, when adopting this perspective of teaching in favor of the establishment of a scientific culture, it is notorious that limitations will arise during the course of the teaching career, since the teaching is inserted in a contentist and formulist tradition. However, the advantages of this "new" way of conceiving science teaching indicate that it contributes to a long-term improvement of society itself.
\end{abstract}

Keywords: culture, bachelardian epistemology, Freire.

\title{
1. Introdução
}

Este trabalho se inicia com a seguinte provocação: até que ponto a educação escolar se consolidou verbosa, palavresca e incomunicável (FREIRE,1999)?

Ao tornar educadores conscientes de sua práxis, é possível perceber que o problema do aluno em não aprender Ciência não se encontra unicamente no mesmo, conforme pregado por uma cultura dominantemente elitista mantida por tradição, durante toda trajetória escolar. Não é culpa de sua falta de "dom" ou puramente de sua má vontade em aprender. Mas sim, de todo um sistema de ensino alimentado por uma tradição positivista que estabelece que sabe Ciência quem domina instrumentos e sabe coletar e reproduzir dados, onde quanto mais informação "absorvida", quanto mais tecnicista, melhor aluno se é.

Essa "Ciência para poucos", ignora a própria construção histórica da Ciência e sua real função perante a sociedade. Dessa forma, ao ensinar tradicionalmente, ignora-se a necessidade da democratização do saber acompanhada de constate reflexão e ação. Desprezase o papel que as Ciências Naturais, assim como qualquer outra Ciência, promovem na cultura dos alunos e na própria construção social. Afinal, a aprendizagem científica trata-se de um processo de enculturação para incorporação não somente de novas habilidades, mas de um novo discurso sobre o mundo e seus elementos (CARVALHO, 2013) que, ao ser capaz de modificar a postura do indivíduo, contribui para a formação de uma cultura geral que se diferencia do senso comum, da chamada cultura de massa.

Destaca-se então a importância da cultura científica no ensino de Ciências e por consequência, a necessidade de se refletir sobre o que se ensina e para que se ensina. Nesse aspecto, a epistemologia desempenha um papel fundamental, visto que os professores ao ensinar, ensinam também suas concepções sobre Ciência e sua natureza (ACEVEDO et al, 
2005). O estudo da epistemologia se valida, ao reconhecer que a prática pedagógica está imersa em perspectivas, em uma diversidade epistemológica, direcionando a formação das concepções dos alunos. Além disso, esta área mostra-se um bom ponto de partida para o estabelecimento de estratégias ou modelos de ensino. Assim, não só a cultura do aluno se torna significativa no processo de ensino-aprendizagem, mas também, a cultura do professor, a qual estabelecerá pontes e por consequência influenciará com suas próprias perspectivas a transição dos patamares culturais de seus alunos.

A necessidade de se promover uma cultura científica aparece timidamente em documentos oficiais que dificilmente são colocados em prática, como os PCN+. No que diz respeito ao ensinar física, por exemplo, dá-se a ideia de que se deve ter a consciência da existência de um sistema excludente, que elimina maior parte dos alunos do ramo das Ciências naturais, mas ainda assim:

[...] mesmo os jovens que, após a conclusão do ensino médio não venham a ter mais qualquer contato escolar com o conhecimento em Física, em outras instâncias profissionais ou universitárias, ainda assim terão adquirido a formação necessária para compreender e participar do mundo em que vivem. (BRASIL, 2012).

Desta forma, não se deve mais ensinar Ciências apenas para uma pequena parcela de futuros cientistas já "pré-determinados" por suas habilidades tecnicistas. Se deve ensinar Ciências para todos, com o intuito de construir cidadãos com potencialidades para promover avanços técnico-científicos e sociais, com novas formas de perceber sua realidade e com possibilidades maiores de se identificar e se engajar no mundo científico como um todo, ou seja, em termos de linguagem, prática, discurso, enfim, como uma postura diversa do senso comum. Estudos em outros campos acadêmicos, como o da sociologia das ciências têm divulgado pesquisas que lidam com as especificidades das formações culturais que provocam distinções entre os indivíduos (por exemplo, Bourdieu, 2010; Lenoir, 2003). Na perspectiva desse trabalho, essas pesquisas estariam mostrando a necessidade de inovações em termos de formação acadêmica do professor, uma vez que as investigações em didática ou em ensino e aprendizagem das ciências problematizam as práticas, noções e, principalmente as posturas que os professores têm tido até o momento, e apontam para mudanças reais em termos de ensino para que aprendizagens significativas ocorram.

Contudo, este trabalho se propõe a refletir sobre a relevância de se ensinar Ciências sob uma perspectiva cultural, formando nos alunos a chamada cultura científica. Para tal, 
pretende-se identificar na epistemologia de Bachelard e Paulo Freire o quanto a cultura é elemento intrínseco do estudo das Ciências, em sua própria construção e no ato de ensinar.

\section{A cultura na Ciência: epistemologia bachelardiana}

Gaston Bachelard (1884-1662), epistemólogo e fenomenólogo francês, esteve imerso nos estudos das Ciências e das Artes. No que se refere a sua epistemologia científica, é crente na possibilidade de uma Ciência como construção racional, sempre em rumo a abstração. Insere uma perspectiva epistemológica histórica, dialética e descontínua, onde sua marca principal é a ruptura.

Em meio as suas principais obras, encontra-se a Filosofia do Não. Nela, Bachelard

sob uma autoanálise, insere a ideia de perfil epistemológico. O perfil epistemológico designa o conjunto de concepções que um indivíduo tem acerca de um conceito específico. Esse conjunto é dinâmico e filosoficamente plural, formado por diferentes escolas filosóficas, onde umas tendem a ser mais presentes que outras, aparecendo em momentos distintos, podendo ir desde concepções prévias imediatas como o substancialismo até um alto grau de abstração como o surrealismo. Além de psicanalisar seu próprio perfil, demonstra que essas mesmas escolas se encontram também na História da Ciência, no desenvolvimento científico de um conceito.

Bachelard propõe que para se psicanalisar um perfil, necessita-se de um conceito específico presente em um espírito individual, ou seja, existe uma relação entre o conceito e a cultura do sujeito. Segundo ele (1978, p. 25) "Insistimos no fato de um perfil epistemológico dever sempre referir-se a um conceito designado, de ele ser válido para um espírito particular que se examina num estádio particular de sua cultura". Assim, o sujeito necessita de constantes reflexões, alterando o estágio de sua cultura, para então progredir sua percepção sobre o objeto científico. É um emaranhado de concepções que deve ser atingido como um todo, contrariando a ideia de acumulo de informações.

Para que o espírito humano vença a inércia de um pensamento estático e progrida cientificamente se tornando jovem e dinâmico, Bachelard (1997) propõe em sua obra Formação do espírito Científico que sejam superados obstáculos epistemológicos. Estes, se encontram presentes nas concepções do sujeito, no olhar que ele tem sobre um objeto científico e sobre a própria constituição da Ciência. Impedem a criação, o realizar de novas ideias.

Os dois termos "perfil epistemológico" e "obstáculo epistemológico" são complementares e cruciais no pensamento diurno de Bachelard. Para que o primeiro progrida 
ou mesmo adquira novas escolas filosóficas, deve ser constantemente vigilante quanto ao segundo, e esse ser constantemente superado pelo espírito científico humano, pois o perfil guarda marcas de obstáculos superados por uma cultura (SOUZA, 2014).

O perfil epistemológico no que se refere a cultura interna do sujeito, carrega em si as marcas de constantes transformações que estabelecem se o espírito progride para uma cultura científica ou não. Para ser científico, o espírito deve ser inovador, criativo e nunca se julgar completo. As zonas epistemológicas se desenvolvem à medida que o sujeito aceita novas concepções, não se mantém inerte a uma única lógica, a uma racionalidade estática.

Bachelard difere cultura erudita de cultura científica. Para ele "[...]a paciência da erudição nada tem a ver com a paciência científica" (BACHELARD, 1997, p.10), pois o dogmatismo preenche a primeira. Mas defende a necessidade do saber, desde que essa cultura erudita seja reelaborada pela científica, isto é, que se estabeleça dinâmica, sem preconceitos, preenchida por um espírito em constante dialética com a abstração. Logo, a verdadeira sabedoria só é alcançada por meio do esforço da abstração, que contrapõe o imediatismo da experiência.

Dessa forma, entende-se que para Bachelard, o sujeito só aprende Ciência, ou seja, só modifica ou adquire suas escolas filosóficas se sua cultura se modificar. Existe então uma forte relação entre o aprender Ciência e a constante reelaboração de uma cultura, tanto individual, quanto geral, pois a própria Ciência se constitui por um perfil também histórico, sendo que cada período do desenvolvimento científico traz em si fortes traços de determinadas escolas filosóficas. Não ocorre superação dos obstáculos epistemológicos sem conscientização e reflexão dos mesmos, assim como a Ciência não progride se não estiver em constante reelaboração.

A cultura que o indivíduo carrega em si e aquela em que se imerge define se ele sabe ou não Ciência. Seu espírito só pode ser científico se percorrer o caminho rumo ao novo, transitar no pluralismo da abstração e romper relações com o senso comum, com o conhecimento imediato. Partindo disso pode-se afirmar que tradicionalismo de um ensino positivista se torna inviável para uma real aprendizagem. O sujeito só aprende Ciência se sua cultura for atingida e modificada, patamares que um ensino conteudista e estático não contempla. Além disso, de acordo com Oliveira (2013, p.109) "Só é possível haver cultura científica se houver alfabetização científica", e essa não se faz em uma educação tradicionalista, mas sim em uma educação humanística, que engloba, ainda de acordo com a autora, três componentes culturais: 1 - uma noção geral sobre determinados conceitos e temas 
da ciência; 2 - uma noção sobre a natureza da atividade científica; 3 - uma consciência do papel da ciência na sociedade e na cultura.

Encontram-se na área de ensino de Ciências, alguns estudos que relacionam a cultura e a epistemologia de Bachelard, como o de Martins (2004), que propõe, inicialmente, em sua tese que existe a necessidade de se explorar a relação entre perfil e cultura sobre o conceito tempo. Baseado nessa perspectiva e na leitura da Filosofia do Não, Souza (2014) propõe em sua tese, investigar a relação entre epistemologia e cultura, a partir da construção do perfil epistemológico, utilizando como conceitos base: espaço e tempo, por apresentarem-se como conceitos congêneres. Para Souza, existe não só um perfil epistemológico, mas também um perfil cultural no qual Bachelard não se aprofundou, mas deixou implícito a todo momento em sua obra ao fazer análise do conceito de massa no decorrer de sua própria cultura, da formação das escolas filosóficas que configuravam seu perfil epistemológico.

Nesse sentido, a cultura que contextualiza o entorno dos alunos pode ser potencialmente formadora das mais variadas concepções, inclusive aquelas que obstaculizarão a compreensão do espírito científico ao qual Bachelard se refere. Devem ser, portanto, em termos deste autor, psicanalisadas, por meio de um processo dialético afetivo-cognitivo entre os saberes prévios e a realidade percebida. Enfim, Bachelard o define como um processo caracterizado por uma catarse, ao fazer referência à psicanálise freudiana, embora esta seja, em alguns pontos, criticada.

Neste cenário, a cultura apontada por Bachelard, que também é a nossa, deve ser conscientizada pelo aluno, para que ele tenha condições de compreender certas problematizações a serem feitas sobre a própria cultura. Das problematizações, abre-se caminho para que algo de novo seja aceito, um novo espírito, uma nova cultura científica. Portanto, trata-se de uma transformação cultural, a partir da qual se concebe um progresso científico e social dos indivíduos.

\section{Cultura na perspectiva Freireana e o ato de ensinar}

Paulo Freire, educador brasileiro, em sua perspectiva de cultura defende “ [...] cultura como o acrescentamento que o homem faz ao mundo que não fez" (FREIRE, 2006, p. 116/117 apud SOUZA, 2014, p.15) Para Freire, em sua proposta de ação cultural e educação dialógica, toda criação humana se coloca como cultura e a educação dialógica, é elemento fundamental para o estabelecimento da mesma.

Na educação dialógica, educador e educando aprendem e ensinam um ao outro, num processo não mais vertical, mas sim de diálogo e respeito. Essa ideia é proposta na obra de 
Freire, a "Pedagogia do Oprimido", onde após uma reflexão de sua praxi, propõe que somente por meio de uma educação dialógica o opressor e o oprimido consigam o patamar da libertação.

O ser humano é então um ser da praxi ação-reflexão que apesar de ter a cultura como elemento intrínseco, necessita ser inserido em uma cultura letrada para a aquisição de uma consciência crítica em prol de sua integralidade quanto ao mundo, sendo que na perspectiva cultural, esse existe envolvido em relações de transformações geradas pelo homem. Ou seja, o homem existe por meio de suas relações com o mundo, e o mundo por meio de suas relações com o homem.

Freire deixa claro sua crítica quanto a educação tradicional, a por ele chamada educação bancária (FREIRE, 1974), onde o aluno é sujeito passivo de acúmulo de informações transferidas pelo professor, mascaradas de conhecimento, sofrendo nada mais que um invasão e destruição cultural advinda dessa extensão do saber.

Para o autor, a escolha metodológica traz consigo uma escolha ideológica acerca da realidade, ou seja, se o aluno aprende por meio de uma prática de transmissão e reprodução, não conseguirá obter a capacidade de reflexão e por consequência, não conseguirá reelaborar sua cultura, não obtendo a tão necessária consciência crítica diante de seu contexto, podendo sempre permanecer em seu estado de oprimido perante a sociedade sem nem ao menos reconhecer sua condição, atribuindo a essa o status de fatalidade.

Em uma visão libertadora e humanística, Freire considera que em uma relação de dois mundos culturais, uma cultura deve respeitar a outra, seja ela letrada ou iletrada, e ambas devem se ensinar. A cultura letrada, deve ser elemento de transformação de consciência no iletrado, ela não pode ser imposta, deve ser apropriada pelas necessidades do próprio indivíduo através de uma educação dialógica.

O conhecimento para Freire se dá na relação entre ser humano e cultura, podendo somente uma ação cultural estabelecer tal dinâmica, ação cultural essa base de sua pedagogia e seu programa de alfabetização de adultos. A ação cultural é o despertar para a realidade do sujeito, é o amanhecer da consciência crítica. Cultura para Freire é a "[...] aquisição sistemática da experiência humana" (FREIRE, 2006, p. 116/117 apud SOUZA, 2014, p.15), que por intermédio da ação cultural deve ser mutável e a partir do momento em que o homem conheci a si e ao mundo que recria ao ter acesso a cultura letrada, deve ser constantemente reelaborada, sem necessariamente desvincular suas raízes, despertando então a consciência crítica do sujeito. 
Assim, baseando-se na ideia de educação dialógica e ação cultural de Freire, é possível obter interpretações sobre a importância da cultura no ensino, e principalmente, o quanto o ensino tradicional se mostra prejudicial para uma educação democratizada e eficaz em seu papel de transformação social.

Nesse sentido, a perspectiva freireana guia o ensino de Ciências para seu real papel perante a sociedade, o de mudança, onde o aluno mesmo ao estudar objetos quantitativos, tem a capacidade de reconhecer e aplicar avaliações qualitativas e críticas, perante sua própria condição e sua relação com o mundo, com a tecnologia e com as possibilidades que lhe são possíveis.

\section{Conclusões}

É possível ver que Bachelard e Freire apesar de se situarem em campos distintos, apresentam similaridades quanto a necessária relevância da cultura que permeia o indivíduo e suas concepções dentro das Ciências, como a necessidade do rompimento entre o senso comum e o conhecimento científico, mostrando que o elemento cultural é fator decisivo no processo de construção/reconstrução de seu saber. Com base nos autores, os fatores criatividade, criticidade e conscientização do sujeito tornam positivo o ensino de Ciências, contrariando o viés tecnicista do ensino tradicional.

Sugere-se através dessas reflexões que sejam repensadas as práticas educativas, considerando que se deva saber o para que ensinar, além de ser dever dos docentes, estar cientes das possibilidades de impacto que suas áreas trazem para a cultura individual de seus alunos e das potencialidades que estes têm, de acrescentamento à cultura geral em que estão imersos.

Ao se adotar essa perspectiva de ensinar em prol do estabelecimento de uma cultura científica, é notório que limitações surgirão ao decorrer do caminhar docente, visto que está inserido em uma tradição conteudista e formulista. Porém, as vantagens dessa "nova" forma de ver o ensino de Ciências contribui para uma melhoria a longo prazo da própria sociedade, pois ela trata de uma dimensão social e cultural que permite alcançar novos patamares cognitivos e afetivos possíveis aos indivíduos (ZANETIC, 1989). Em outros termos, trata-se da formação de um olhar que, distinto do senso comum, permite um refinamento racional e subjetivo, portanto, cognitivo e afetivo, que todos os sujeitos podem alcançar. 


\section{Referências}

ACEVEDO, J. A.; VÁZQUEZ, A.; PAIXÃO, M. F.; ACEVEDO, P.; OLIVA, J. M.; MANASSERO, M. A. Mitos da didática das ciências acerca dos motivos para incluir a natureza da ciência no ensino das ciências. Ciência \& Educação, v. 11, n. 1, p. 1-15, 2005.

FREIRE, Paulo. Educação como prática da liberdade. 23a ed. Rio de Janeiro: Paz e Terra, 1999.

BACHELARD, G. A filosofia do não. Tradução. J. J. M. Ramos. São Paulo: Abril Cultura, 1978. (Os pensadores)

BACHELARD, G. A formação do espírito científico: contribuição para uma psicanálise do conhecimento. Rio de Janeiro: Contraponto, 1997.

BOURDIEU, P. O Poder Simbólico. 13ª edição. Rio de Janeiro: Bertrand Brasil, 2010.

BRASIL. Ministério da Educação. Secretaria da Educação Média e Tecnológica. Parâmetros Curriculares Nacionais $+(P C N+)$ - Ciências da Natureza e suas Tecnologias. Brasília: MEC, 2002. Disponível em:

$<$ http://portal.mec.gov.br/seb/arquivos/pdf/CienciasNatureza.pdf > Acesso em 22 de agosto de 2017.

CARVALHO, A. M. P. de. Habilidades de Professores para promover a Enculturação Científica. Contexto \& Educação, v.22, n.77, p.25-49, 2013.

FREIRE, P. Educação como prática da liberdade. $23^{\mathrm{a}}$ ed. Rio de Janeiro: Paz e Terra, 1999.

FREIRE, P. Pedagogia do oprimido. Rio de Janeiro: Paz e Terra, 1974. LENOIR, Timothy. Instituindo a Ciência: a produção cultural das disciplinas São Leopoldo, RS: Editora UNISINOS, 2003.

GODINHO, V. M. Prefácio. In: ENSAIOS: humanismo científico e reflexão filosófica. Lisboa: Sá da Costa, 1971b. v. 4, p. i-xxix.

Maurício, P. Valente, B. Argumentos para uma humanização do ensino das ciências. Ciênc. Educ., Bauru, v. 19, n. 4, p. 1013-1026, 2013

LENOIR, T. Instituindo a Ciência: a produção cultural das disciplinas São Leopoldo, RS: Editora UNISINOS, 2003

MARTINS, A. F. P. Concepções de estudantes acerca do conceito de tempo: uma análise à luz da epistemologia de Gaston Bachelard. 2004. Tese (Doutorado em Educação) - Faculdade de Educação, Universidade de São Paulo, São Paulo, 2004.

OLIVEIRA, C. A educação científica como elemento de desenvolvimento humano: uma perspectiva de construção discursiva. Revista Ensaio, v.15, n. 02, p. 105-122, 2013 
SOUZA, P. H. de. Epistemologia e cultura no ensino de física: desvelando os conceitos de tempo e espaço. 2014. Tese (Doutorado em Ensino de Física) - Ensino de Ciências (Física, Química e Biologia), Universidade de São Paulo, São Paulo, 2014.

ZANETIC, J. Física também é cultura. 1989. 252f. Tese (Doutorado em Educação, Faculdade de Educação, Universidade de São Paulo) - FEUSP, SP. delo para Sites). 